\title{
Un circuito transhumántico entre la costa de Pisagua y el borde occidental de la Pampa del Tamarugal
}

LaUtaro NúÑez A.*, VJera ZlataR* y Patricio NúÑ̃z H.*

Recientemente hemos detectado la existencia de un circuito transhumántico entre grupos preagrícolas que utilizaban la costa con cierta estabilidad y se complementaban con estacionamientos temporales en ambientes de vertientes, valles y pampas al interior de la costa en el perfil costa-altiplano de la provincia de Tarapacá (norte de Chile).

Para evaluar esta hipótesis se delimitó el espacio comprendido entre la costa de Pisagua Viejo y los cursos o quebradas de Jazpampa y Tiliviche que drenan en este sector al Pacífico por la quebrada de Camiña, desde el nivel de base regional establecido en la Pampa del Tamarugal, que precisamente es cortada por los cursos antes mencionados.

Se inició la prospección en relación a este circuito en las cotas bajas del distrito Pisagua Viejo, donde se obtuvieron muestras orgánicas que darán los límites temporales del potente yacimiento homólogo "convergente" y que servirán, a su vez, como pautas homotaxiales en relación a los campamentos estacionales internos o "divergentes" del circuito que nos preocupa.

La prospección en Saya, o zonas de vertientes inmediatamente al interior de Pisagua Viejo (a $12 \mathrm{~km}$ ), reafirmó nuestra hipótesis con las evidencias de ocupaciones tempranas que antes habíamos verificado en la vertiente de Quiuña.

Junto a las vertientes de Quiuña Bajo detectamos tres campamentos básicos. Los dos más altos ofrecen posibles viviendas formadas por depresiones asociadas a montículos bajos de basuras. Hemos encontrado escasas manos y morteros en superficie. En Quiuña Bajo-1 o campamento de mayor densidad, harneamos una cuadrícula de inspección. El perfil demostró un estrato de basuras de $10 \mathrm{~cm}$ de espesor. La fecha radiocarbónica colocará a

* Programa de arqueología y museos, Universidad de Chile, Antofagasta. la industria como parte superior del contexto, es decir, que el tiempo por recibir datará a la industria específica. La abundante presencia de artefactos líticos en proceso de elaboración, bien terminados y/o con usos evidentes, explican claramente que se trata de campamentos que, junto con aprovechar los recursos bióticos locales, utilizan materia prima lítica adyacente (cuarzo, sílice, basalto y otros).

Sin embargo, en todos los sitios registrados hemos observado que la frecuencia de artefactos líticos de superficie es de extraordinaria densidad en relación a los artefactos y litos ubicados en los perfiles de prueba de los depósitos estratigráficos. Parece que en todos los sitios el acumulamiento de desperdicios orgánicos fue paralelo a la manufacturación de artefactos. La actual mayor densidad en superficie eventualmente se debe a la erosión eólica, que en la localidad es intensa. Aunque los depósitos estratigráficos son débiles, con fluctuaciones en todos los sitios revisados que van desde los 10 a los 70 $\mathrm{cm}$ de promedio, el desgaste eólico logró eliminar la capa superficial de material orgánico, decantando a los materiales líticos hasta formar una "cubierta" de protección natural. Este hecho nos permitió la obtención de numerosas herramientas líticas (puntas de tipologías diversas, lascas con retoques, pequeños núcleos, instrumentos, preformas, artefactos cortantes) y otros indicadores. Estos datos, conjuntamente con el material orgánico subyacente, servirán para el análisis contextual y temporal de la formación socioeconómica correspondiente y sus relaciones con los diversos estacionamientos del circuito transhumántico. Se adjunta un Apéndice con una tipología aproximada de todos los sitios.

En Quiuña Alto, a $20 \mathrm{~km}$ de la costa de Pisagua, ubicamos dos campamentos densos en ambas terrazas que dominan la localidad. Quiuña Alto-1 presenta sectores con basuras bajas y estructuras del mismo patrón de Quiuña Bajo y con la misma frecuencia de manos y morteros. Estos rasgos, más un conjunto de puntas con bases sofisticadas que incluyen tipos pequeños, lo hacen diferir de Quiuña Alto-2, emplazado en la terraza opuesta. 
En Quiuña Alto-1 hemos excavado una cuadrícula para muestreo de análisis radiocarbónico, oportunidad en que detectamos varios depósitos débiles, pero con restos mayoritarios de producción marítima.

Quiuña Alto-2 tiene dos sectores de ocupación bien determinados, separados por un sector con escasa basura. Las viviendas son poco visibles. Destacamos como ejemplo de seriación el predominio del tipo de punta de base escotada. En general, ya en las localidades Quiuña Alto podemos entrever que una seriación de rasgos indicadores -teniendo en mente la llegada de los fechados- nos permitirá situar los cambios cronológicos e industriales del circuito transhumántico, poniendo énfasis en los cambios funcionales de las clases de artefactos en relación al microambiente utilizado.

Estas diferencias serán mejor detectadas una vez que se realicen los análisis cuantitativos de basuras, en especial sobre los desperdicios de origen terrestre (fauna y vegetación) que son más difíciles de identificar que los marítimos. Entre estas basuras aparecen artefactos muy indicadores que sugieren algunos cambios significativos ocurridos en cada uno de los campamentos. Por ejemplo, en la cuadrícula de muestreo de material orgánico del campamento Quiuña Alto-2 aparecieron asociados a la muestra para fechamiento dos especímenes de anzuelos de espina de cactos. En Tiliviche-I-B, la cuadrícula de igual muestreo ofreció un fragmento de anzuelo de concha, que sabemos data la ocupación más temprana de Punta Pichalo, con un tiempo casi seguro de 6000 años AP (determinación radiocarbónica de Quiani).

En el sector de Tiliviche, a $30 \mathrm{~km}$ al interior de Pisagua Viejo, la ocupación se explica por los recursos locales derivados del estrangulamiento de la quebrada, con afloramientos hídricos y materia prima utilizable en la elaboración de artefactos líticos. Es quizás el área de mayor densidad de aprovechamiento estacional $\left(500 \mathrm{~m}^{2}\right)$, extendidos en la pendiente y terraza principal.

Aquí hemos definido tres sectores básicos con abundancia de manos y morteros de sección cóncava-cónica y estrecha, típicos de los sitios del área. Las estructuras se conforman por depresiones asociadas a montículos con desperdicios más considerables, con alturas que llegan a los $60 \mathrm{~cm}$. Se trata de un patrón similar a los sitios con viviendas ya mencionados.
Tanto la cantidad de viviendas y de fogones en Tiliviche hacen prever que la ocupación fue muy constante. Es probable que estos yacimientos representen un período de mayor duración que los campamentos anteriores, por lo menos, la estratificación es sensiblemente mayor. Sin embargo, aunque intuimos un uso estacional insistente en el sitio, sólo contaremos con una fecha radiocarbónica.

Las industrias líticas de Tiliviche-I-A-B y C son importantes por su carácter no perturbado, señalando una notable variabilidad tipológica. Ciertamente que aquí están representados la mayoría de los tipos tempranos presentados por Bird (1943), para el primer poblamiento costero con control estratigráfico. Agregamos que las comparaciones en cuanto a formas, funciones, y tamaños con industrias de la quebrada de Tarapacá, laguna del Huasco y otros sitios andinos, nos hacen presuponer que son partes eventuales de circuitos mayores.

Finalmente, este estudio abarcará la zona de afloramientos de agua situados en el borde occidental de la Pampa del Tamarugal, al sur de Tiliviche, siempre al interior de la costa de Pisagua. Se trata del distrito Aragón, en la cabecera de la quebrada de Jazpampa, que nace un poco al sur -cerca de Zapiga- y drena en la quebrada de Camiña.

El campamento Aragón-1 tiene un aspecto semimonticulado y extendido en su sector de máximo desarrollo. Superficialmente difiere de los yacimientos anteriores, por cuanto ofrecía a nuestro reconocimiento escasa talla lítica. Es notable la variedad de materia prima para la elaboración de preformas bifaciales, fragmentos de hojas-cuchillos y pequeñas puntas lanceoladas. Otro rasgo indicativo, que lo difiere de los otros campamentos en estudio, es la ausencia de depresiones circulares formadas por uso habitacional. La ocupación teóricamente está justificada por las características del nicho ecológico ubicado en la cabecera de la quebrada de Jazpampa (vertiente).

En Aragón hasta hoy los recursos de agua son suficientes para dar un ambiente vegetacional en una quebrada que abruptamente ha erosionado el nivel de la pampa estéril.

El desarrollo del trabajo de caza y recolección se ve aquí aparejado por la posibilidad de recoger importante materia prima vegetal y lítica. La cuadrícula de inspección de estratos y posteriormente el corte 
contextual ofreció un contenido económico cultural no agropecuario en un perfil de $5 \mathrm{~m}$ de largo. La ocupación detectada en este corte-1 demuestra una constante muy peculiar en los estratos inferiores, con indicadores básicos como son los anzuelos de cactos. La profundidad del corte-1 varía entre los 50 y $180 \mathrm{~cm}$ con rasgos arcaicos persistentes caracterizados por la falta de cerámica y la presencia de manos y morteros tempranos en estratos inferiores y superiores.

La muestra radiocarbónica datará el comienzo de la ocupación de este sitio, que difiere en cuanto al patrón de asentamiento de los sitios anteriores, aunque indudablemente se ajustará al modelo de transhumancia como parte del circuito que estudiamos. Esto en razón a que el corte-1 presentó una densa estratificación con gran popularidad de pescados (cabezas, espinas, escamas y cueros). Es notoria la escasez de mariscos y conchas. Además, hay que considerar que las herramientas recuperadas no siempre están vinculadas estrictamente a la explotación marítima (v.g., cepillos). Los restos óseos son escasos, lo que hace sospechar que la caza no fue intensiva. Sin embargo, la presencia de restos vegetales silvestres (totora y otros) es cuantiosa y tipifica el aprovechamiento de los recursos locales paralelos a la materia prima lítica con artefactos especializados en los trabajos locales internos a la costa.

Estacionalmente determinados, grupos establecidos en el litoral de Pisagua ascendían -entre otros sitios- a Aragón-1, donde la zona de vertiente producía un cuadro ecológico altamente favorable para la recolección y la caza eventual, así como el trabajo de talla lítica. El hecho de que en el corte-1 encontráramos abundantes restos de pescado puede ser por la deficiencia de caza terrestre local. Esto permite suponer que las condiciones de alimentación natural eran difíciles. La falta de alimentación local parece ser evidente. Esto explicaría el traslado de víveres desde la costa aledaña.
En consecuencia, el causal de asentamiento se explicaría como un estacionamiento (agua potable) previo al ingreso del circuito que conduce al aprovechamiento estacional de la Pampa del Tamarugal con sus enormes reservas alimenticias, unidas a otros focos de explotación al interior de la pampa señalada. Aparte de esto, la persistencia de la ocupación de Aragón-1 se debería buscar en los recursos locales otorgados por las vertientes, lo que, en general, no ocurre en el litoral desértico al sur de Pisagua Viejo. La presencia en el corte-1 de abundante fibra vegetal podría sugerir que el estacionamiento se explica por la acumulación de esta fibra, altamente importante en la explotación marítima y terrestre antes del conocimiento de los medios de producción asociados a la agricultura. Los morteros podrían evidenciar algunas prácticas de alimentación de vegetales silvestres por medio de molienda. Finalmente, el uso de material lítico local podría ampliar la idea, en el sentido de que el sitio está también vinculado con la elaboración de herramientas y útiles relacionados con el incremento de los medios de producción.

Una cantidad aproximada a los 5000 artefactos y muestras columnares de desperdicios se han registrado en 10 sitios del circuito; todos mantienen peculiaridades que darán base a un plan de excavaciones ajustado con los datos radiocarbónicos y las reevaluaciones de varios sitios más meridionales en la Pampa del Tamarugal.

Por ahora, si bien las tipologías son similares a varias industrias andinas (v.g., Complejo Huasco), es seguro postular que estos dos grupos dependían de campamentos convergentes en Pisagua Viejo y estacionalmente transhumaban a microambientes internos en quebradas fértiles, oasis de vertientes y Pampa del Tamarugal, en donde, apoyados por la alimentación marítima, lograban complementar su subsistencia con recursos vegetales y materias primas para la elaboración de útiles y herramientas.

\section{REFERENCIAS CITADAS}

BIRD. J., 1943. Excavations in Northern Chile. Anthropological Papers of the American Museum of Natural History XXXVIII, Nueva York. 